\title{
The Use of Simulation Tools in the Development and Design of Near-Location Systems
}

\author{
Andrey B. Borzov ${ }^{1 *}$ and Grigory L. Pavlov ${ }^{1}$ \\ ${ }^{1}$ Bauman Moscow State Technical University, 2nd Baumanskaya str., 5/1, 105005, Moscow, Russia
}

\begin{abstract}
Based on the principles of didactics, the role of student activity and independence in the learning process is shown. The approaches are determined and the place of simulation modeling in the development and design of systems is shown. Examples of modeling systems are given. Special attention is paid to the principle of controlled independent work of the student.
\end{abstract}

\section{Introduction}

Of all the definitions that currently exist that characterize learning, the most successful is V.V. Davydov [1]:

"Education is a focused process of managing the active educational and cognitive activity of students in mastering professional knowledge, skills, developing creative abilities, shaping the worldview and personal qualities necessary for students to independently master the profession."

Education is a two-way process in which the student and the teacher interact (Fig. 1). It is in the course of interaction that the education, upbringing and development of a person as a specialist and person as a whole is systematically and purposefully carried out. This joint activity of the teacher and the subjects of learning, has as its goal the development of the latter, the formation of their knowledge, skills, experience, elements of the worldview, future professional or educational activities.

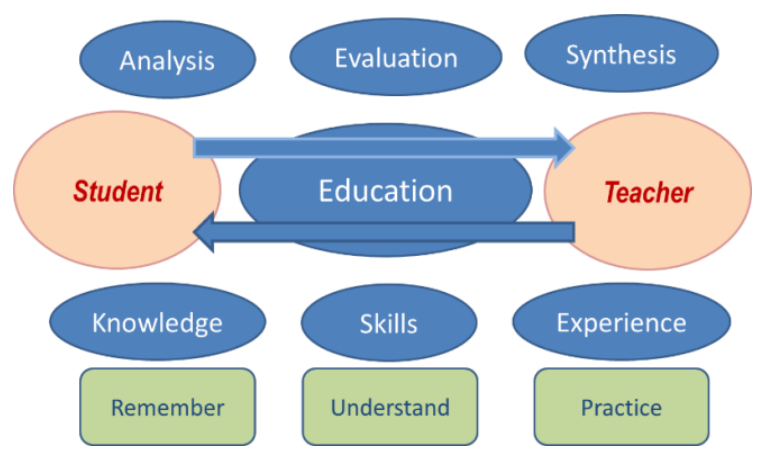

Fig. 1. A two-way process in which the student and the teacher interact

* Corresponding author: wave@sm.bmstu.ru 
The most important aspect in the above definition, as applied to the tasks of higher professional education (HPE), set today and the conditions in which they have to be solved, is, in our opinion, the student's activity and his independence or, as is now accepted, motivation [2].

Let us explain the meaning of activity and independence. It is no secret that the current conditions for obtaining a student's education are such that he is forced to combine the learning process with the search for livelihoods. In this sense, he is forced to combine a time schedule and a training schedule. Moreover, often the priority is not the educational process, and the work itself may be far from specialized professional activity. At the same time, the value of education is fully recognized by the student, because the ultimate goal, in his understanding, is a diploma that allows you to acquire a higher social status and ensures career growth. The ultimate goal of training in fact, as noted above, is the mastery of professional knowledge, skills, the development of creative abilities, the formation of the worldview and personal qualities necessary for independent mastery of the profession.

That is, provided that the student has an active need for education (and not just a document about him), the modern technology of the educational process should allow the student to independently choose the form of knowledge. We make a reservation right away that we are not supporters of a cult, the so-called distance education, which is essentially extramural, but has acquired a different form in connection with the development of information technology. The disadvantages of extramural education and its compulsion are well known [3]. However, the objective need for the student to work encourages universities to introduce elements of distance education and full-time education. This measure, we emphasize, is forced and caused by the current state of the economy and the attitude to the education and upbringing of citizens.

Given the foregoing, we will try to formulate the main approaches to the formation of the educational process at the department. As the main principles, we will continue to consider activity and independence.

\section{Main part}

From the point of view of general didactics, the educational process consists of seven elements: the purpose of training, the content of training, trainees, trainers, methods, means and forms of training $[4,5]$.

The purpose of training is a system of knowledge, skills, experience, that are formed in accordance with the model of a professional specialist and state educational standards. In modern terminology, the goal is the formation of competencies in various fields of professional and social activity. element of the system of goals of academic discipline, etc. (Fig. 2).

The basis of the educational process at the present stage should be independent work in a convenient place, pace and time. The educational process should provide the student with the opportunity, and in a number of disciplines, the obligation to communicate both with the teacher and with each other, for example, students' research work (NIRS), course design, qualification work. It is obvious that with this approach to the student high demands are made on personal qualities: activity, perseverance, determination, honesty, etc. 


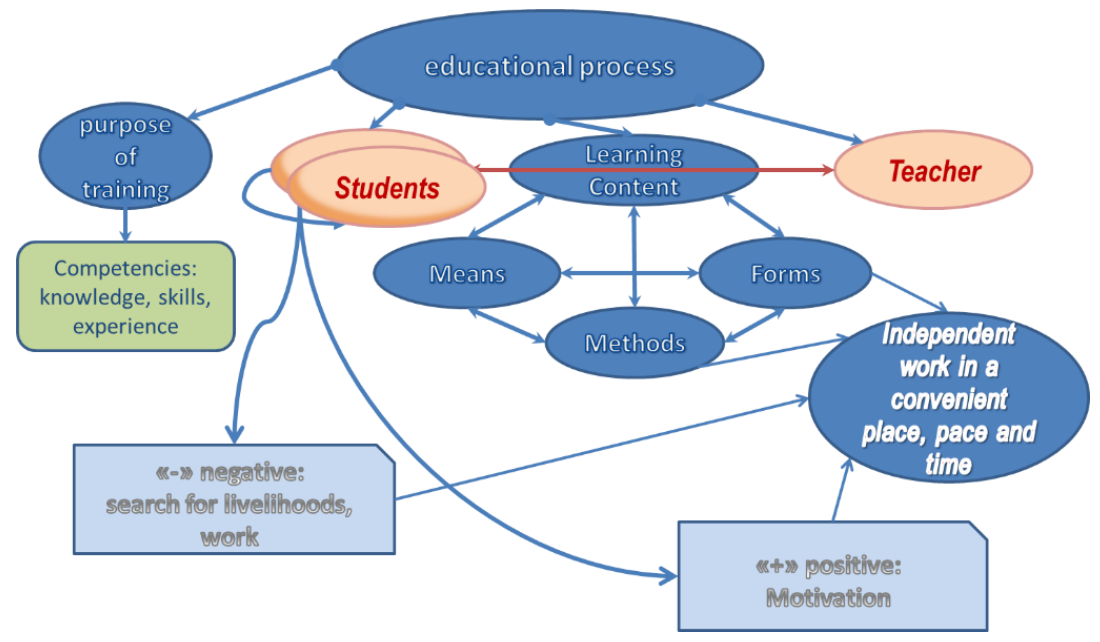

Fig. 2. Educational process and independent work.

The student must possess the basics of the methodology and technique of independent work, independent acquisition and replenishment of knowledge with the highest motivation. In addition, for effective training, they must have the skills to work with modern technical means and information technology. Thus, studying at a university requires a certain readiness of a student to study, i.e. starting level of education (initial set of knowledge, skills, experience), material and technical support of the workplace and confidence in their demand in the future. Modern information technologies allow the student to move from the object of pedagogical influence to the subject of training, i.e. become an active participant in the educational process. That is, there is a development and continuation of the traditions of teaching at Bauman Moscow State Technical University: "the Russian method of teaching crafts".

A modern teacher should be able to see the technological, organizational, socioeconomic and socio-psychological possibilities of obtaining the maximum pedagogical result. Teacher functions depend on the accepted learning model. Teachers can be not only full-time university professors, but also people with high professional achievements and involved on the conditions of part-time or hourly wages. The main task of the teacher is: management of students' independent work; the formation of motivating motives; setting goals and objectives; transfer of knowledge, experience; organizational activities; organization of interaction between students; control of the learning process. The teacher should analyze the assessment of students in the form and content of individual courses and take them into account when developing educational materials. It helps the student in drawing up a personal learning path, i.e. activates and directs the student's independent work. A variety of functions and the diversity of the teacher's activities require their specialization. But the main thing that is required from the teacher is not to be a passive source of educational information, but to skillfully (actively) direct the student's independent work. And, of course, we must not forget about the educational role of the teacher in the universal sense $[6,7,8]$.

For modern teaching based on modeling, five general didactic teaching methods are applicable: information-receptive, reproductive, problematic presentation, heuristic and research. They cover the entire totality of pedagogical interaction between teacher and student.

Informational and receptive is a traditional teaching method. Its implementation consists of a verbal explanation of the teacher and a visual image of a part of the information in the form of graphs, tables, formulas, etc. on a training board or poster. Currently, the 
implementation of the method is carried out through the verbal presentation of the teacher, accompanied by multimedia tools (presentations, demonstration of electronic models, films, etc.). All this allows not only to verbally convey the necessary information, but also to demonstrate it clearly, which allows to provide the necessary level of assimilation of new educational material. Thus, the information-receptive method requires different means (verbal, visual, practical) and forms of manifestation (speaking and listening, showing and watching), but always its didactic essence is the same - presenting the finished information to the students and conscious perception and memorization by the students. This method is most often used to explain to students the essence of the modeling method, the principles underlying the modeling system, algorithms [7].

The reproductive teaching method is a method of educational activity carried out according to a specific instruction, with the reproduction of knowledge and practical skills acquired by students earlier or directly in the learning process.

The reproductive method is aimed at the formation of skills in students. This is achieved by applying the knowledge available to students on the model, in the framework of the situations proposed by the teacher. With the help of the task system, the activities of students are organized, providing for the repeated reproduction of their knowledge, as well as practical experience. The essence of the reproductive method is that it is aimed at acquiring skills through the system of tasks organized by the teacher. One of the varieties of the method is the "do as I" principle, while the teacher formulates the task and shows, by way of example, the method and options for solving it using simulation tools. Thus, the basis of the reproductive method consists in repeating and reproducing a certain mode of activity. The work of students is to complete tasks based on an already prepared sample.

The reproductive method is aimed at enriching students with knowledge, abilities and skills, the formation of basic mental operations (abstraction, analysis, synthesis, etc.). However, despite the effectiveness of obtaining the necessary experience, this method does not guarantee the development of creative abilities, does not allow them to be purposefully and systematically formed.

Problem-based training is training in which the teacher, systematically creating problem situations and organizing students' activities to solve educational problems, provides the optimal combination of their independent search activity with the assimilation of readymade conclusions of science. Problematic training is aimed at the formation of cognitive independence of students, the development of their logical, rational, critical and creative thinking and cognitive abilities. Based on the laws of the psychology of thinking, the logic of scientific research, it contributes to the development of the student's intellect, his emotional sphere and the formation of a worldview on this basis. Problem-based learning presupposes not only the assimilation of the results of scientific knowledge, but also the path of knowledge itself, the ways of creative activity. The basis of problem-based learning is the personality-activity principle of the organization of the learning process, the priority of the search educational and cognitive activity of students.

The heuristic teaching method is a method aimed at students finding independently answers to the questions posed by the teacher. In this case, the main goal is to design students own meaning, purpose and content, organization and awareness of the need for training. [9, 10]

Learning based on the heuristic method is the continuous discovery of the new.

The tasks of the heuristic teaching method include:

the formation and creation of students own personal experience aimed at obtaining knowledge of the future;

constructing each student's own meaning and filling the learning process.

The heuristic teaching method combines cognitive creative activity. This is due to the fact that the teacher does not give students ready-made knowledge, but provides them with 
an object, the knowledge of which they must find independently, obtain information and master it. Physical phenomena, functional circuits, etc. can act as an object. On the basis of the object, students create an activity product in the form of text, product, concept, etc. In the framework of the heuristic method, the result of a child's creative activity is not predictable, since it completely depends on his basic knowledge and personality. After presenting the result to the teacher, the students compare it with the already known achievements in this field and comprehend it.

The ultimate goal of the heuristic teaching method is not to obtain specific knowledge and skills, but to implement the student's creative self-realization.

Thus, one of the main methods that allows students to be creative in the process of teaching a subject is the heuristic method.

Of particular importance today is research training, which acts as a factor in the student's self-development and self-determination, and has a significant impact on the personality and professional development of a specialist [8]. The main feature of research training is to intensify students' academic work, giving it a research, creative character and, thus, to convey to students the initiative in organizing cognitive activities. The main goal of research training is the formation of abilities to independently, creatively master and rebuild new ways of working in any area of human activity. In research teaching, research is not just a set of teaching methods and techniques, but its content and meaning. Students, therefore, form the idea of research not just as a set of private cognitive tools that allow them to solve cognitive problems productively, but as a leading way of contact with the outside world and even more broadly - as a lifestyle. Therefore, modern education is no longer required to simply incorporate research teaching methods into educational practice, but to focus on the development of research abilities, specially organized training of students in research skills.

Means of education. In the educational process, both traditional teaching aids are used: books (in paper and electronic form), which have appeared relatively recently: online training materials, computer-based training systems in conventional and multimedia versions that require active interaction.

A special role in technical education belongs to laboratory works and workshops, independent educational research, and projects. It is these types of educational work that form the skills of independent work in the field of professional activity. At the same time, not all modern systems, in particular, systems of near location (SNL), can be presented in the form of physical systems and laboratory samples. In a whole series of cases, it is much more efficient to use their mathematical and simulation models. Using models allows a detailed analysis of the processes occurring in the SNL and identification of the model and the real system. In modern conditions, almost the entire process of design, experimental testing, testing and operation is accompanied by modeling at different levels.

Educational - material basis. This is an important component of education, inextricably linked with the content and methodology of the educational process. The experience of all developed countries of the world has clearly demonstrated that the systematic expansion and complication of the educational and material subsystem of an educational institution is an indispensable condition for the normal functioning of education and the increase in its economic and social role.

The educational material basis includes material conditions, teaching aids and objects of study, i.e. a set of material and technical means necessary for training in the established areas of training in accordance with the curriculum. It includes training and educational support facilities; laboratory equipment, technical teaching aids, textbooks, teaching aids and other teaching materials. Modern education is largely based on new information technologies, the importance of the educational material base is especially growing. 
Simulation [11] is a research method in which the real system is replaced by a model that describes the real system with which the experiments are carried out with sufficient accuracy in order to obtain information about this system. Such a model can be used both for a single test and for a given set of them. The results will be determined by the random nature of the processes.

This is a special case of mathematical modeling for systems or objects for which, for various reasons, analytical models have not been developed or creating an analytical model is fundamentally impossible. Moreover, part of the object can be represented by a physical object, and part by its model.

In the general case, a simulation model is a logical and mathematical description of an object that can be used to experiment on a computer for the purpose of designing, analyzing, and evaluating the functioning of an object.

As a rule, simulation modeling is used in cases:

expensive or impossible to experiment on a real object;

it is impossible to build an analytical model: the system has time, causal relationships, consequence, nonlinearities, stochastic (random) variables;

it is necessary to imitate the behavior of the system in real or model time.

When developing and designing SBL, the use of simulation models is justified in the following cases [12]:

formation of input SBL signals reflected from various objects;

design of antenna devices;

development and debugging of signal processing devices, including complex ones;

development and implementation of neural-like signal processing systems;

imitation of real operating conditions of the SBL;

other tasks that are statistical in nature.

The above list is not exhaustive, it only reflects the range of tasks that are most often encountered in the development and design of SNL.
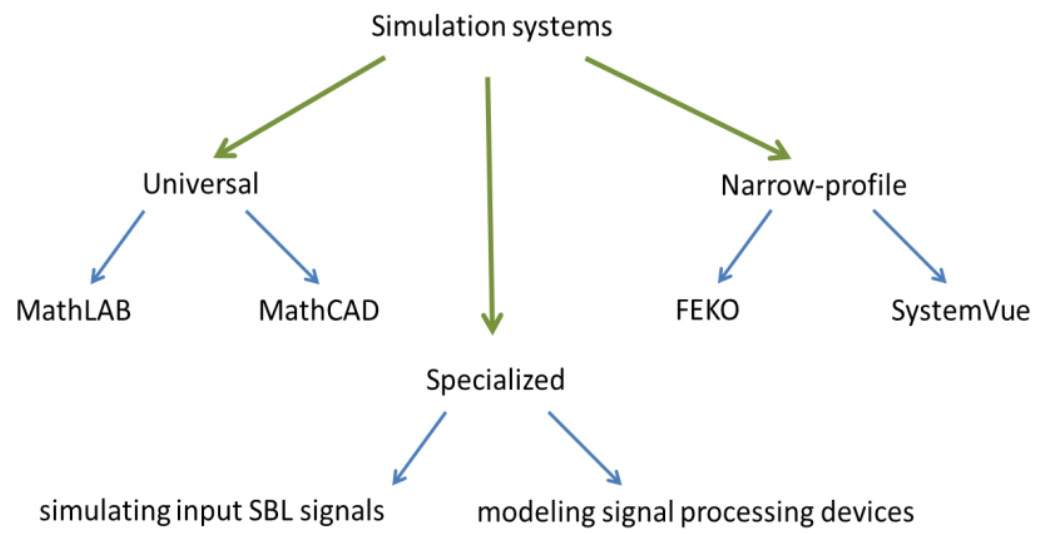

Fig. 3. The working window of the input signal modeling system.

In the educational process are used as universal modeling programs, such as: MathLab [13], MathCAD [14], so specialized, narrow-profile modeling systems: FEKO [15], SystemVue [16] and others. Of course, these simulation systems allow you to perform the simulation of a whole complex of systems, including near-location systems. However, there are a number of tasks that cannot be resolved, either in universal or in specialized modeling systems (Fig. 3). 
In this case, you have to create your own modeling and design environment, which provides a solution to the tasks. So, for example, the department has developed several modeling systems for the development and design of SBLs: a system for simulating input SBL signals (Fig. 4) [17-20] scattered by various objects; a system [12, 21, 22] for modeling signal processing devices (Fig. 5 and 6) and others.

You must understand that from the point of view of the student, any system of modeling and design is, to a certain extent, a "black box" that can solve his problems with design. At the same time, the understanding of the physical principles and algorithms for solving the equations of the model incorporated into the system is either not taken into account or simply ignored. In this regard, the role of the teacher is to, in the process of interacting with the student, force the latter, in the course of independent work with the modeling system, to study the principles laid down in this system. Of course, the didactic techniques and methods discussed above are intended to provide basic knowledge on modeling methods and the algorithms that are embedded in them. However, with an increasing amount of information, it can neither be conveyed by traditional methods, nor comprehended and put into practice. It is controlled independent work in the process of full-time interaction of the student with the teacher that can achieve the goals of the educational process, that is, the formation of competencies.

A positive effect is achieved with the public protection of the results of laboratory work, home back and NIRS in the form of a round table or seminar. This has a great educational effect, when a student not only brings the results of work and answers the questions of the teacher, but reports them to an audience like him and answers the questions of his colleagues and teachers. In this case, he rethinks his own knowledge and experience, learns to discuss, upholds the decisions made.

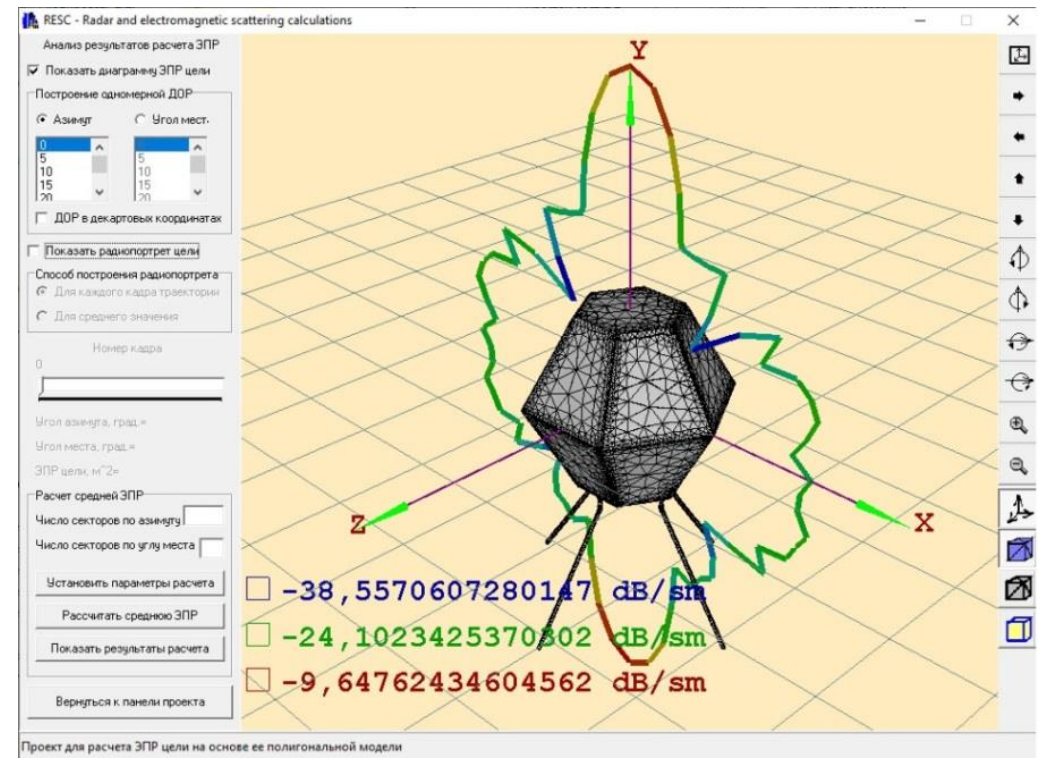

Fig. 4. The working window of the input signal modeling system. 


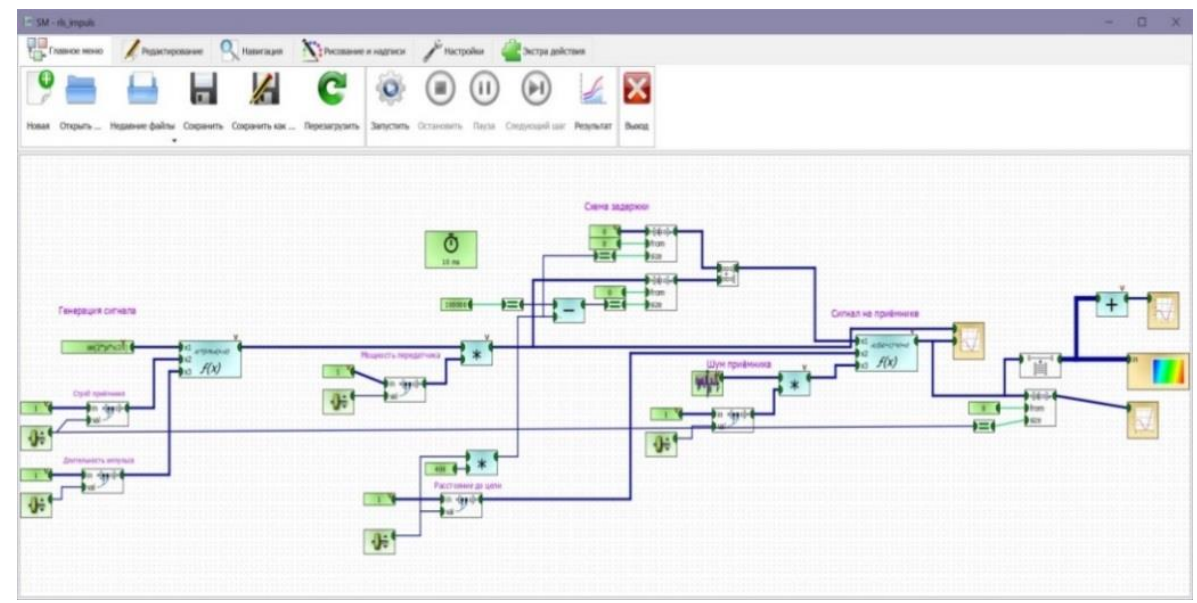

Fig. 5. Block diagram window of signal processing device

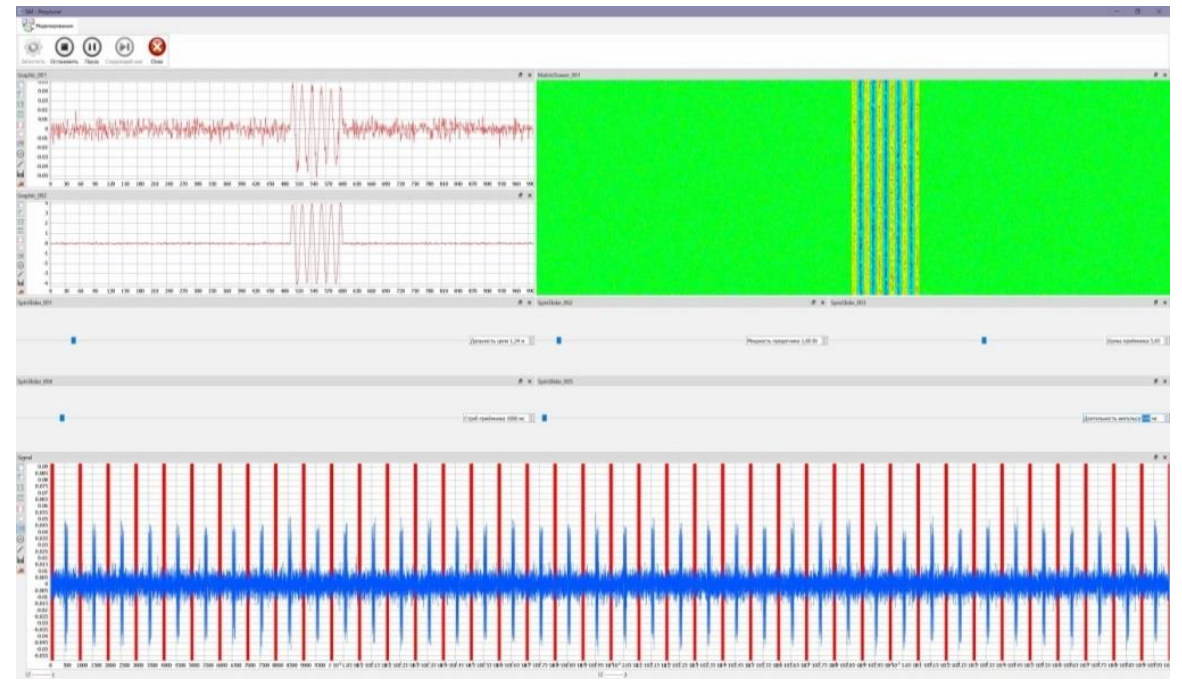

Fig. 6. Simulation results of a signal processing device

\section{Conclusion}

The use of simulation tools in teaching students the development and design of SNL consists in solving the following problems (represents the following educational technology):

- within the framework of lecture courses: obtaining knowledge about SBL as a whole and the principles of their work, methods for solving the problems of developing and designing SNL as a whole and its subsystems (information-recipient method);

- within the framework of seminars, to consolidate the theoretical material of lectures and gain skills in solving particular problems of design and development, learn to plan an experiment, both full-scale and imitative (information-reproductive, problematic method);

- within the framework of practical exercises and laboratory work, to acquire skills and abilities, under the direct supervision of a teacher, to solve typical practical problems of designing and developing SNL using simulation tools on a computer and laboratory stands (heuristic method); 
- in the framework of educational research, course design, homework, qualification work, independently consolidate knowledge and skills in the development and design of SNL (problem-research method), while the role of the teacher consists in consulting support and monitoring of current results.

\section{References}

1. Russian pedagogical encyclopedia: In 2 vols. / Ch. ed.. - M.: Big Russian Encyclopedia, 1993. - P.568 (1993)

2. V. Richardson, Constructivist teaching and teacher education: Theory and practice, in Constructivist teacher education, pp. 13-24, Routledge (2005)

3. Pedagogical Encyclopedic Dictionary / Ch. ed. B.M. Bim Bad; Editorial: M.M. Bezrukikh, V.A. Bolotov, L.S. Glebova et al. M.: Big Russian Encyclopedia, 2003 .- p. 141 (2203)

4. T.M. Kozhanova, B.A. Karev, G.Z. Khabibullina, I.D. Ibragimov, L.G. Khisamiyeva, N.V. Zaytseva \& M.A. Kulkova, The didactic construct of design technologies in the educational process of modern university, in Mediterranean journal of social sciences, 6(2 S3), p. 225 (2015)

5. V.A. Shershneva, L.V. Shkerina, V.N. Sidorov, T.V. Sidorova \& K.V. Safonov, Contemporary Didactics in Higher Education in Russia, in European journal of contemporary education, 17(3), pp.357-367 (2016)

6. A. Kolmos, Facilitating change to a problem-based model, in International Journal for Academic Development, 7(1), 63-74 (2002)

7. B. Sabitzer \& S. Strutzmann, Brain-based Programming, in 2013 IEEE Frontiers in Education Conference (FIE), October 2013, pp. 1163-1169, IEEE, (2013)

8. E.F. Zeer \& A.V. Streltsov, Technological platform for realization of students' individual educational trajectories in a vocational school, in International Electronic Journal of Mathematics Education, 11(7), pp. 2639-2650 (2016)

9. S. Wenda, D. Yunfeng \& L. Ke, Application of heuristic teaching method in electrical and electronic experimental teaching $[\mathrm{J}]$, in Experimental Technology and Management, p. 4 (2012)

10. S. Wang, R. Han, M. Zhang, X. Fan \& S. Zhang, Improving Teaching Efficiency with Heuristic Teaching Method in Information Technology, in Advances in Information Technology and Education, pp. 454-458, Springer, Berlin, Heidelberg (2011)

11. R. Shannon, Systems Simulation: The art and science, Prentice Hall, June 1, 1975, p. 387 (1975)

12. A.B. Borzov, K.P. Likhoedenko, B.S. Lobanov, I.V. Muratov, G.L. Pavlov, V.B. Suchkov \& V.K. Khokhlov, Voprosy modelirovaniia avtonomnykh informatsionnykh sistem blizhnei lokatsii [Problems of modeling of autonomous information systems near the location], Moscow, OOO NITs «Inzhener», OOO «Oniko-M», Publs (2010)

13. MathLAB Homepage, https://www.mathworks.com/help/?s tid=hp_ff_1_doc.

14. MathCAD Homepage, https://www.mathcad.com/en/academic

15. FEKO Homepage, https://altairhyperworks.com/product/FEKO

16. SystemVue Homepage, https://www.keysight.com/en/pc-1297131/systemvue$\underline{\text { electronic-system-level-esl-design-software?cc=RU\&lc=rus }}$ 
17. A.B. Borzov, V.B. Suchkov, B.I. Shakhtarin \& Y.A. Sidorkina, Mathematical modeling and simulation of the input signals of short-range radar systems, in Journal of Communications Technology and Electronics, 59(12), pp. 1356-1368 (2014)

18. V.V. Akhiyarov, V.M. Orlov, G.P. Slukin \& V.Y. Shustikov, Application of the integral equation method for determination of electromagnetic field scattered from perfectly conducting bodies of revolution calculation in resonance area, in Электромагнитные волны и электронные системы, 10(7), pp. 15-20 (2005)

19. V.V. Akhiyarov, A.B. Borzov, V.B. Suchkov, B.I. Shakhtarin \& Y.A. Sidorkina, Calculation of the backscattered field by the method of the physical diffraction theory in the problem of diffraction from impedance objects, in Journal of communications technology and electronics, 60(12), pp. 1297-1304 (2015)

20. V.B. Suchkov, Object-oriented method of determination of complex coefficients of reflection of elements of polygonal model of targets, in Systems and means of communication, television, and broadcasting (2013)

21. A.B. Borzov, V.B. Suchkov \& A.V. Sokolov, Digital modeling of the input signals of near-radar systems from complex radar scenes, in Journal Of Radio Electronics, p. 4 (2004)

22. M.S. Selezneva, K.A. Neusypin \& I.V. Muratov, Research on Criteria for the Degree of Controllability of the State Variables of Dynamic Systems Models, in 2019 26th Saint Petersburg International Conference on Integrated Navigation Systems (ICINS), May 2019, pp. 1-4, IEEE (2019) 